\title{
THERMOANALYTICAL EVALUATION OF ESSENTIAL OILS OF THE LEAVES FROM EUCALYPTUS SPP SUSCEPTIBLE AND RESISTANT TO GLYCASPIS BRIMBLECOMBEI
}

Geisa Liandra de Andrade de Siqueira1, Marcelo Lazzarotto*2, Maryana Fernandes², Ana Claudia da Silveira², Simone Rosa da Silveira

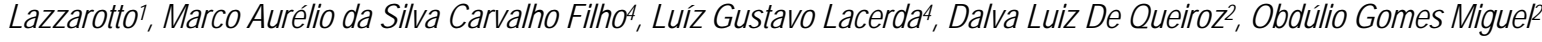

\author{
1 Universidade Estadual de Ponta Grossa - Ponta Grossa - PR - Brasil. \\ ${ }^{2}$ EMBRAPA Florestas - Colombo, PR - Brasil. \\ ${ }^{3}$ Universidade Federal do Paraná - Curitiba - PR - Brasil. \\ 4 Universidade Positivo - Curitiba - PR - Brasil. \\ *marcelo.lazzarotto@embrapa.br
}

\begin{tabular}{|c|c|}
\hline $\begin{array}{l}\text { Acepted } \\
\text { Published in }\end{array}$ & $\begin{array}{l}28 / 06 / 2016 \\
01 / 10 / 2016\end{array}$ \\
\hline $\begin{array}{l}\text { Keywords } \\
\text { thermal analysi } \\
\text { essential oils } \\
\text { Glycaspis brim }\end{array}$ & ecombei \\
\hline
\end{tabular}

DOI 10.18362/bjta.v5.i1.1

\begin{abstract}
Euacalyptus is part of the national economy. This is a natural source that provides pulp for papermaking, coal for the steel industry and bioactive compounds used in various medical and industrial areas. The essential oil extracted from leaves is an important product obtained from Eucalyptus. This work evaluated essential oil extracted from leaves of Eucalyptus resistant and susceptible to Glycaspis brimblecombei using thermal tools. Samples of essential oils were extracted from crushed leaves of E. pellita (resistant) and E. camaldulenses (susceptible) by Clevenger method. The oils were analyzed by physicochemical characterization, thermogravimetry and differential thermal simultaneous analysis (TGA-DTA) and differential scanning calorimetry (DSC). The TGA curves of the essential oil from E. camaldulensis and commercial showed similarity and show that the major constituent can be 1,8-cineole. However, the TGA curves of the E. pellita essential oil has different pattern. In DSC, changing the endothermic peak of the commercial oil indicates the presence of other components or additives. The results indicate that these Eucalyptus essential oils had different chemical composition and the 1,8cineole can be the reason of resistance and susceptibility to $\mathbf{G}$. brimblecombei attack. Further studies will be performed to characterize these samples.
\end{abstract}

\section{Introduction}

Because of its economic value, Eucalyptus spp. are cultivated mainly in tropical zone. In Brazil, this culture is economically important for the steel and paper industries [1,2]. This economical source is being threatened by the entry of exotic pests [3].

Among the pests is the Glycaspis brimblecombei, originated in Australia (Erro! Fonte de referência não encontrada.B). This insect is sucking habits damaging eucalyptus leaves and facilitates the proliferation of fungi, shown in Erro! Fonte de referência não encontrada.A e $1 C[4,5]$. Insect eggs and nymphs of $G$. brimblecombei are found on the leaves of most species of Myrtacea including Eucalyptus. Among the Eucalyptus the more susceptible to insect attack is $E$. camaldulensis and hybrid clones [6]. 
BRAZILIAN JOURNAL OF THERMAL ANALYSIS

Braz. J. Therm. Anal. Vol. 5 No. 1

DOI 10.18362/bjta.v5.i1

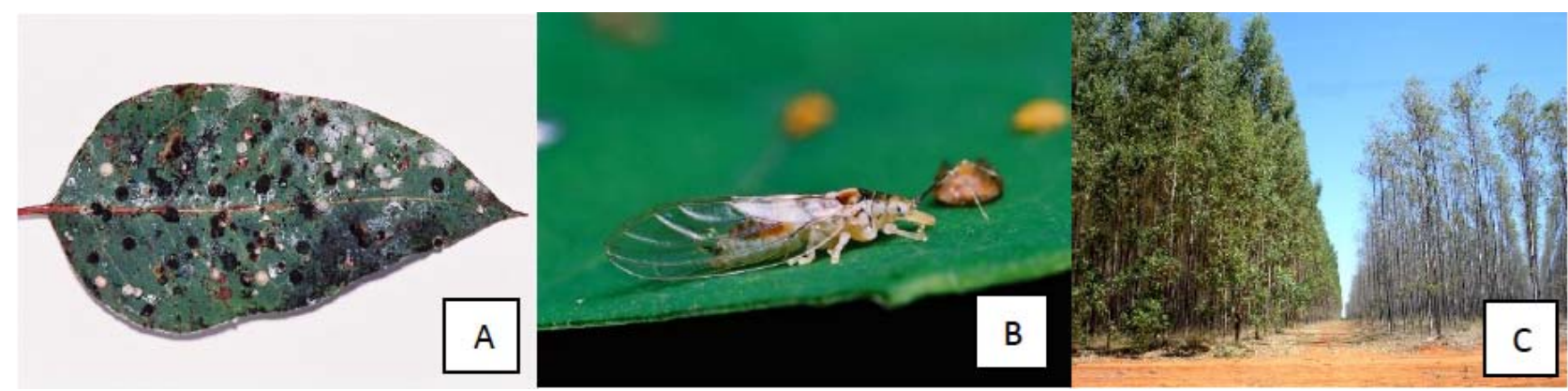

Figure $1 \mathrm{~A}$ - attacked leaf; B - adult of Glycaspis brimblecombei; C - resistant 257 eucalyptus (left) and susceptible (right) to Glycaspis brimblecombei

The essential oil of Eucalyptus has compounds produced for its defense. Between the bioactive compounds have phenolic compounds and terpenoids which have a certain degree of repellent, antimicrobial and pesticide activity $[7,8]$.

Thermal analysis refers to various techniques performed in order to monitor the behavior of a sample as a function of time or temperature, with thermoanalytics instrumentation is currently used in a wide range of scientific investigations. Among the most widespread techniques are thermogravimetry (TGA), the differential thermal analysis (DTA) and differential scanning calorimetry (DSC) [10].

These techniques can be applied in numerous industrial activities, such as chemical, petrochemical, pharmaceutical, cosmetics, food and even for essential oils industries [11,12]. In the latter case, thermal analysis allows essential oils characterization, assess to their thermal behavior and stability and investigation of possible tampering [13].

Field observations indicated that E. pellita was slightly susceptible to $G$. brimblecombei. Nevertheless, this insect affected the plantation of the $E$. camaldulensis, in the same field. These observations motivated this study. The aim of this work was to analyze essential oils extracted from the leaves of $E$. pellita (resistant) and E. camaldulensis (susceptible). Therefore, we used thermogravimetry and differential thermal simultaneous analysis (TGADTA) and differential scanning calorimetry (DSC).
The essential oils extracted were compared with the commercial oil.

\section{Materials and Methods}

\section{Plant Material and Essential Oil Extraction}

The leaves of Eucalyptus spp. were collected in May 2014 in Vazante-MG $\left(17^{\circ} 41^{\prime} 39.39^{\prime \prime} S\right.$, $45^{\circ} 33^{\prime} 45.23$ "W). The neighboring species E. pellita and $E$. camaldulensis were selected because they exhibited different degrees of infestation by $G$. brimblecombei. Essential oils were extracted from approximately $300 \mathrm{~g}$ of crushed leaves. In this process, we used hydrodistillation method by Clevenger apparatus. It is a simple apparatus in which leaves remain in contact with water under high pressure and temperature, so the constituents of the essential oil volatilize. By steam distillation they are carried into the condenser, where they change their physical state. In the collection tube there are the outlet water and the essential oil fluid, so there is a possible separation by density difference [14]. The commercial essential oil of Eucalyptus globulus from Sigma-Aldrich ${ }^{\circ}$ Lot \# MKBF5278V was used as the standard sample.

\section{Physicochemical characterization}

The samples underwent physicochemical characterizations. Densities of the essential oils were determined using an analytical balance relative to distilled water at $22^{\circ} \mathrm{C}$ as comparative. The refractive index was determined with the 
Braz. J. Therm. Anal. Vol. 5 No. 1

refractometer type Abbe Refractometer Carl Zeiss at $20^{\circ} \mathrm{C}[15,16]$

\section{Thermogravimetric study (TG/DTA)}

Thermogravimetry and differential thermal simultaneous analysis (TGA-DTA) were performed using the DTG-60 / TG-DTA equipment (Shimadzu, Japan). The methodology was adapted according to the literature [17]. The analysis conditions were: heated from $30^{\circ} \mathrm{C}$ to $200^{\circ} \mathrm{C}$, synthetic air flow of 50 $\mathrm{ml} \mathrm{min}{ }^{-1}$, about $10 \mu \mathrm{L}$ of initial volume, weight of approximately $5 \mathrm{mg}$ and heating rate was $20^{\circ} \mathrm{C} \mathrm{min}$ 1 , in alumina crucibles. Approximatelly $0.1 \mathrm{mg}$ of alpha alumina was added to the empty crucible and then filled with eucalyptus oil to prevent from samples boiling. The results were processed using the software TA 60WS Shimadzu.

\section{Differential scanning calorimetry (DSC)}

The DSC curves were obtained from the DSC60 equipment (Shimadzu, Japan). The methodology was adapted according to the literature [18]. The analysis conditions were: heating from $30^{\circ} \mathrm{C}$ to 200 ${ }^{\circ} \mathrm{C}$, air flow of $50 \mathrm{ml} \mathrm{min}^{-1}$, the heating rate was 10 ${ }^{\circ} \mathrm{C} \mathrm{min}{ }^{-1}$, the sample volume was about $10 \mu \mathrm{L}$, weight of approximately $5 \mathrm{mg}$, in aluminum crucibles sealed with a little hole on the lid. Approximatelly $0.1 \mathrm{mg}$ of alpha alumina was added to the empty crucible and then filled with eucalyptus oil to prevent from samples boiling. The results were processed using the software TA 60WS Shimadzu.

\section{Results and Discussion}

\section{Physicochemical characterization}

After extraction, the samples underwent physicochemical analysis. According to Table 1, the
DOI 10.18362/bjta.v5.i1

yields of essential oils extraction were $0.89 \%$ ( $E$. pellita) and $2.19 \%$ (E. camaldulensis). The essential oil of the species with major infestation has a lower density $\left(0.8513 \mathrm{~g} / \mathrm{cm}^{3}\right)$, whereas E. pellita essential oil has a density of $0.8827 \mathrm{~g} / \mathrm{cm}^{3}$. The trade pattern is the densest oil compared to the natural essential oils. The refractive indices for the commercial oil and $E$. camaldulensis essential oil have the same value (1.5880). E. pellita has a lower index (1.4660).

\section{Simultaneous thermogravimetry and differential thermal analysis (TG-DTA)}

The Figure 2 shows the thermogravimetric curve (TGA) of the commercial and the extracted essential oils. There are distinct behaviors of mass loss at different temperatures between the samples. Essential oil of $E$. pellita had mass losses from 68 to $180{ }^{\circ} \mathrm{C}$. Nevertheless, essential oil of $E$. camaldulensis ranged from 57 to $157^{\circ} \mathrm{C}$, showing similarity with commercial essential oil (68 to 143 $\left.{ }^{\circ} \mathrm{C}\right)$. These results suggest that the resistance or susceptibility of these varieties of Eucalyptus to $G$. brimblecombei may be correlated to the composition of the essential oils.

Similar mass loss of Eucalyptus essential oil and cineol, its main component, was observed in literature [18], at temperature from 55 to $145^{\circ} \mathrm{C}$. This result was similar to the TGA showed in Figure 2, for samples (b) and (c). This similarity of the curves may indicate that the cineole is the major compound of samples from E. camaldulensis and commercial essential oils samples. In previous studies it is reported that 1,8 -cineole is the main chemical compound of $E$. camaldulensis essential oil (28 to $84 \%$ ) [19]. Sample (a) curve in Figure 2, shows a higher final temperature of the mass loss. This result means that E. pellita essential oil has a different chemical composition. 


\section{(C) BTA BRAZILIAN JOURNAL OF THERMAL ANALYSIS}

Braz. J. Therm. Anal. Vol. 5 No. 1
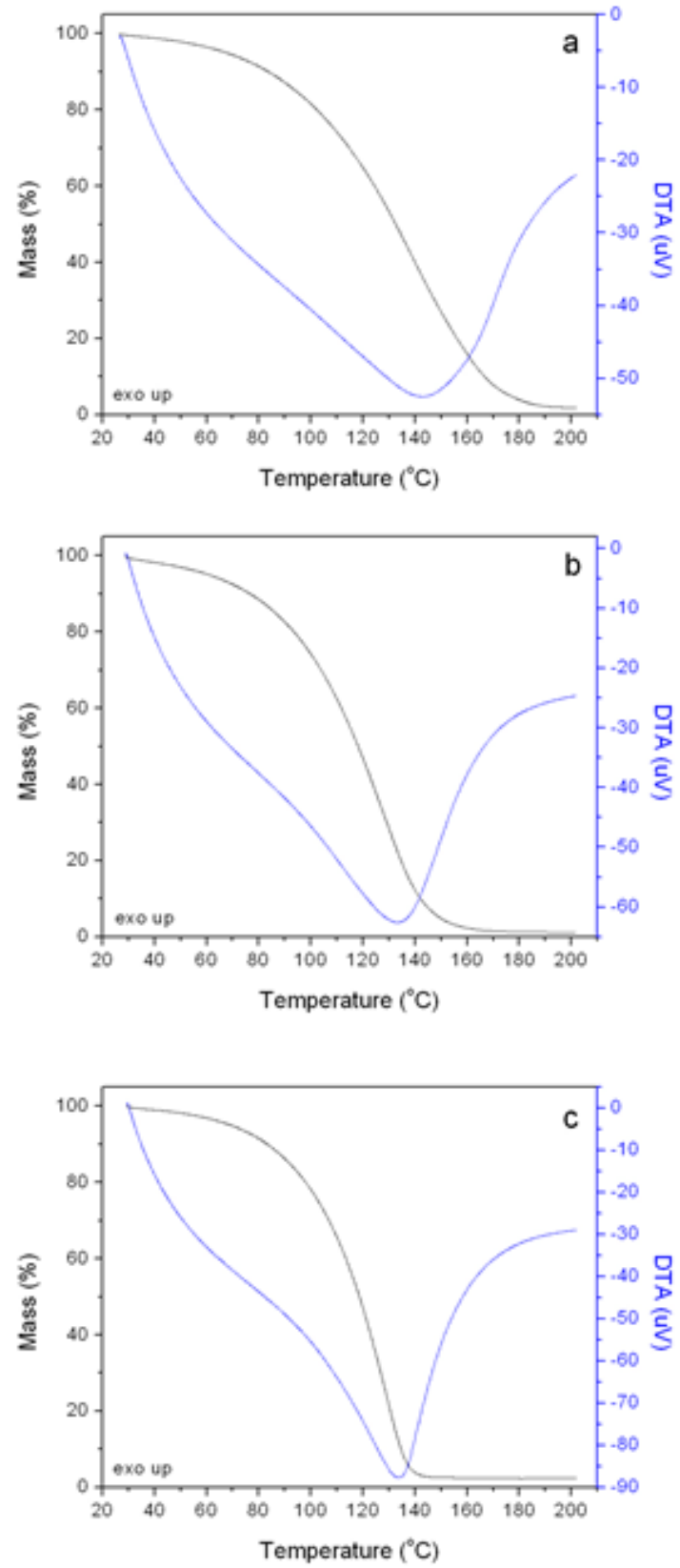

Figure 2 (a),(b),(c)

The essential oils showed endothermic peaks in DTA curves, Figure 2. In this analysis it was identified that it contains the peaks at a temperature of approximately $187^{\circ} \mathrm{C}$ for sample (a) of $167^{\circ} \mathrm{C}$ for
DOI 10.18362/bjta.v5.i1

sample (b) and $147{ }^{\circ} \mathrm{C}$ for sample (c). These figures show that the sample (a) was more resistant toward increasing temperature to a certain value when compared to the other samples.

\section{Differential scanning calorimetry (DSC)}

In the DSC curve, shown in Figure 3, there is a sharp change in the sample (c) as compared to samples (a) and (b). The event observed in commercial oil was more intense than in other extracted oils. There is a difference in the composition, indicating the presence of other components or additives in the commercial essential oil [20].

The sample (a) showed the endothermic peak at a higher temperature compared with the samples (b) and (c). These results support the observations through the TGA curves that E. pellita essential oil has different chemical composition of the $E$. camaldulensis and commercial essential oils.

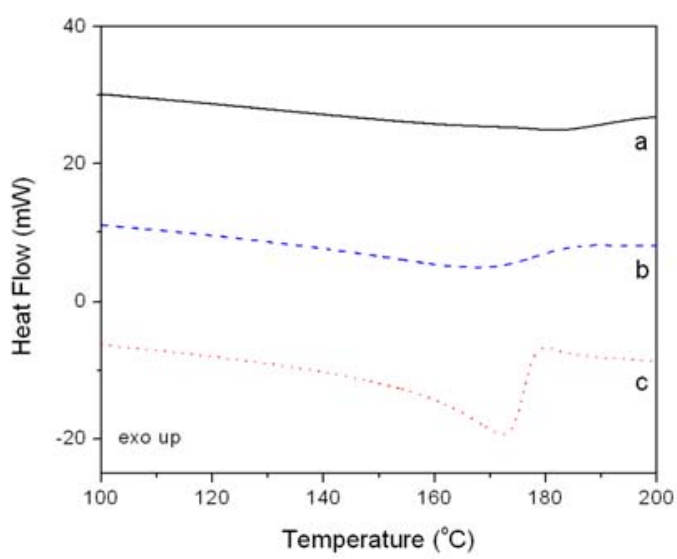

Figure 3

\section{Conclusions}

E. pellita is more susceptible to $G$. brimblecombei, a forest plague, than $E$. 
Braz. J. Therm. Anal. Vol. 5 No. 1

camaldulensis. The refractive index of the essential oils of $E$. camaldulensis and commercial has the same results, differing of $E$. pellita essential oil; indicating differences in chemical composition between the samples. The thermogravimetry and differential thermal simultaneous analysis (TGADTA) was showed similarity between the essential oils of E. camaldulensis and commercial and curves may indicate that the 1,8-cineole is the major compound of this samples. However, the TGA-DTA curves of the E. Pellita essential oil demonstrate that this has a different chemical composition. The results of DSC curves collaborate with the observations made using the TGA. The results indicate that these Eucalyptus essential oils were different and the 1,8-cineole can be the compound of resistance and susceptibility to $G$. brimblecombei attack. Further studies will be performed to characterize these samples and identify the compounds present in these essential oils.

\section{Acknowledgements}

The authors thank for Embrapa Forestry, CAPES, CNPq, Votorantin Siderurgia and Positive University.

\section{References}

[1] Lutinski JA, Lutinski CJ, Garcia FRM. Primeiro registro de Glycaspis brimblecombei Moore 1964, (Hemiptera: Psyllidae) em Eucalipto no Estado de Santa Catarina, Brasil. Ciência Rural. 2006:36:653-655.

[2] Siddiqui BS, Sultana I, Begum S. Triterpenoidal constituents from Eucalyptus camaldulensis var. obtusa leaves. Phytochemistry. 2000:54:861-865.

[3] de Queiroz Santana DL, Burckhardt D. Introduced Eucalyptus psyllids in Brazil. Journal of Forest Research. 2007:12:337-344.

[4] Silva AL, Filho OP, Dorval A, Castro CKC. Dinâmica Populacional de Glycaspis brimblecombei e Inimigos Naturais em Eucalyptus spp., Cuiabá-MT. Floresta e Ambiente. 2013:20:80-90.

Disponível em http://www.bjta.com.br/2016-vol-5-ed-1
DOI $10.18362 /$ bjta.v5.i1

[5] Firmino-Winckler DC, Wilcken, CF, Oliveira, NC, Matos, CAO. Biologia do psilídeo-de-concha Glycaspis brimblecombei Moore (Hemiptera, Psyllidae) em Eucalyptus spp. Revista Brasileira Entomologia. 2009:53:144-146.

[6] Brennan EB, Hrusa GF, Weinbaum SA, Levison W Jr Resistance of Eucalyptus species to Glycaspis brimblecombei (Homoptera: Psyllidae) in the San Francisco by area. Pan-Pac Entomol. 2001:77:249-253.

[7] Batish DR, Singh HP, Kohli RK. Eucalyptus essential oil as a natural pesticide. Forest Ecology and Management. 2008:256:2166-2174.

[8] Gilles M, Zhao J, An M, Agboola S: Chemical composition and antimicrobial properties of essential oils of three Australian Eucalyptus species. Food Chemistry. 2010: 119(2):731-737.

[9] Lacerda LG, Azevedo JAM, Carvalho Filho MAS, Demiate IM, Schnitzler E, Vanderberche LPS, Soccol CR. Thermal characterization of partially hydrolyzed cassava (Manihotesculenta) starch granules. Brazilian Archives of Biology and Technology. 2008:51:1209-1215.

[10] Schnitzler E, Kobelnik M, Sotelo GFC, Bannach G, lonashiroM. Thermoanalytical study of purine derivatives compounds. Eclética Química. 2004:29:71-78.

[11] Hazra A, Dollimore D, Alexander K. Thermal analysis of the evaporation of compounds used in aromatherapy using thermogravimetry. Thermochimica Acta. 2002:392:221-229.

[12] Hazra A, Alexander K, Dollimore D, Riga A. Characterization of some essential oils and their key components. Journal of Thermal Analysis and Calorimetry. 2004:75:317-330.

[13] Monteiro OS, Souza AG, Soledade LEB, Queiroz N, Souza AL, Filho Mouchrek VE, Vasconcelos AFF. Chemical evaluation and thermal analysis of the essential oil from the fruits of the vegetable species Pimenta dioica Lindl. J Therm Anal Calorim. 2011:106:595-600.

[14] Silveira JC, Busato NV, Costa AOS, Costa Jr, EF. Levantamento e análise de métodos de extração de óleos essenciais. Enciclopédia Biosfera. 2012:8:2038-2052.

[15] Brasil. Farmacopeia Brasileira. $5^{a}$ ed. Brasília: Anvisa; 2010.

[16] Kanias GD, Kilikoglou, V, Tsitsa E, Loukis, A, Radioanal, J. Determination and statistical analysis of trace element and 


\section{(C) BTA BRAZILIAN JOURNAL OF THERMAL ANALYSIS}

Braz. J. Therm. Anal. Vol. 5 No. 1

DOI 10.18362/bjta.v5.i1

active constituent concentrations in the plant Eucalyptus camaldulensis dehnh ( $E$. rostratus schlecht). Journal of Radioanalytical and Nuclear Chemistry. 1993:169:483-491.

[17] Hijo AACT, Costa JMG da, Silva EK, Azevedo VM, Yoshida MI, Borges SV. Physical and thermal properties of oregano (OriganumVulgare L.) essential oil microparticles. Journal of Food Process Engineering. 2015:38:1-10.

[18] Hazra A, Alexander K, Dollimore D, Riga A. Characterization of some essential oils and their key components: Thermoanalytical techniques. Journal of Thermal Analysis and Calorimetry. 2004:75:317-330.

[19] Ozel MZ, Yilmaz S, Ergin C. Analysis of Eucalyptus camaldulensis volatiles from turkey using DTD-GC-MS. Journal of Essential Oil Bearing Plants. 2010:13(3):297-312.

[20] Lis-Balchin M, Deans SG, Eaglesham E. Relationship between Bioactivity and Chemical Composition of Commercial Essential Oils. Flavour and Fragrance Journal. 1998:13:98104. 